\title{
Preparation and Reaction of Partially Benzylated 2-Azido-2-deoxy-L-xylopyranose ${ }^{\dagger}$
}

\author{
Hiroyoshi Kuzuhara, Hiroshi Ohrul and Sakae Emoto \\ The Institute of Physical and Chemical Research, Wako-shi, Saitama \\ Received August 28, 1972
}

\begin{abstract}
2-Azido-3,4-di-O-benzyl-2-deoxy-L-xylopyranose (XV) was prepared. Oxidation of $\mathrm{XV}$ with methyl sulfoxide and acetic anhydride was examined.
\end{abstract}

It was described in the previous paper of this series $^{1)}$ that 2-azido-3,4,6-tri-O-benzyl-2-deoxy$\mathrm{D}$-altropyranose had been prepared and oxidized with methyl sulfoxide and acetic anhydride to afford 2-azido-3,4,6-tri-O-benzyl-2-deoxy-Dallono-1,5-lactone with a concomitant inversion of the azido group at $\mathrm{C}-2$. It should be reasonable to assume that the azido group inverted from axial to equatorial attachment in $\mathrm{Cl}(\mathrm{D})$ conformation of the hexopyranose although the unequivocal conformational analysis could not be achieved.

Pentopyranose derivatives generally are in more flexible conformation than hexopyranose derivatives are, because pentopyranoses lack the hydroxymethyl group at C-5*. Therefore, it is interesting to know what products partially benzylated 2 -azido-2-deoxy-pentopyranose gives on oxidation with dimethyl sulfoxide and acetic anhydride. It is especially meaningful to choose partially benzylated 2-azido-2-deoxyL-xylopyranose as a pentopyranose derivative in connection with our present project directed towards the synthesis of polyoxins, a novel group of antibiotics, since polyoxins contain 2-amino-2-deoxy-L-xylonic acid (polyoxamic acid) as a constituent structure. ${ }^{\text {) }}$

This paper deals with the preparation of 2-azido-3, 4-di-O-benzyl-2-deoxy-L-xylopyranose (XV) and its oxidation with methyl sulfoxide and acetic anhydride. In a prelimi-

+ Syntheses with Azido Sugars. Part VI. Part V see reference 1 ).

* The hydroxymethyl group at $\mathrm{C}-5$ in a hexopyranose greatly contributes to its favored conformation. ${ }^{2+31}$ nary experiment, it was unsuccessful to prepare 2-azido-2-deoxy-L-xylofuranose derivative from 2-O-methanesulfonyl derivative of methyl 3O-benzyl-5-O-methoxycarbonyl-L-lyxofuranoside $^{5)}$ by substitution of the sulfonate with azido ion.**

Difficulty of the introduction of an azido group to $\mathrm{C}-2$ of the aldopentose derivative prompted us to employ 3-azido-3-deoxy-hexose derivative as a starting material and to cleave it between $\mathrm{C}-1$ and $\mathrm{C}-2$ to 2-azido-2-deoxypentose derivative. The employed material, 3-azido-3-deoxy-1 ,2: 5, 6-di-O-isopropylidene$\beta$-L-idofuranose $(V)$, had been synthesized in syrupy state by Brimacombe et al. ${ }^{7}$ via several reaction-intermediates including 1,2:5,6-di-Oisopropylidene- $\beta$-L-talofuranose (III) and its 3-O-tosylate (IV). As the reaction scheme taken by Brimacombe et al. did not seem to secure the supply of a large quantity of III, we developed a new pathway to III. 3-O-Benzyl1,2-O-isopropylidene- $\beta$-L-talofuranose $(\mathrm{I})^{\mathrm{8}}{ }^{2}$ was treated with dry acetone and anhydrous cupric sulphate to afford 3-O-benzyl-1,2:5,6-di-Oisopropylidene- $\beta$-L-talofuranose (II) in good yield. Removal of benzyl group of II by hydrogenolysis with palladium on carbon $(10 \%)$ as catalyst resulted in the concomitant loss of isopropylidene group. A trace of acid contained in the catalyst might cause the migration of 1,2-O-isopropylidene group to 2,3 position and the following hydrolysis of

\footnotetext{
** It is well known with aldopyranose derivatives that polar effect of two oxygen atomes at $\mathrm{C}-1$ interferes the substitution on $\mathrm{C}-2$ with a charged nucleophile. ${ }^{5}$, This will be the case in this furanose derivative.
} 

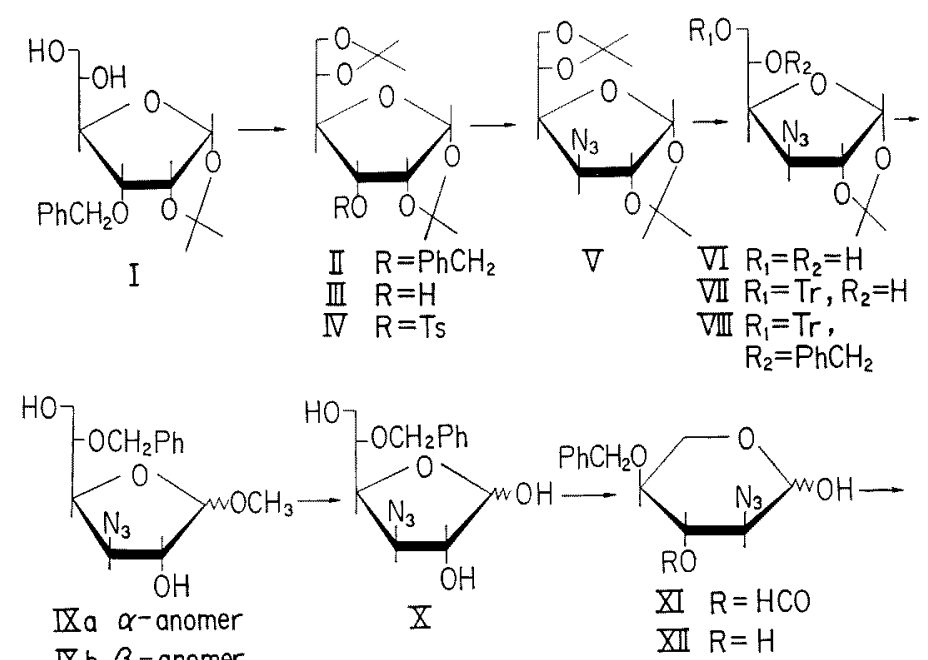

$\mathbb{X}$ b $\beta$-anomer

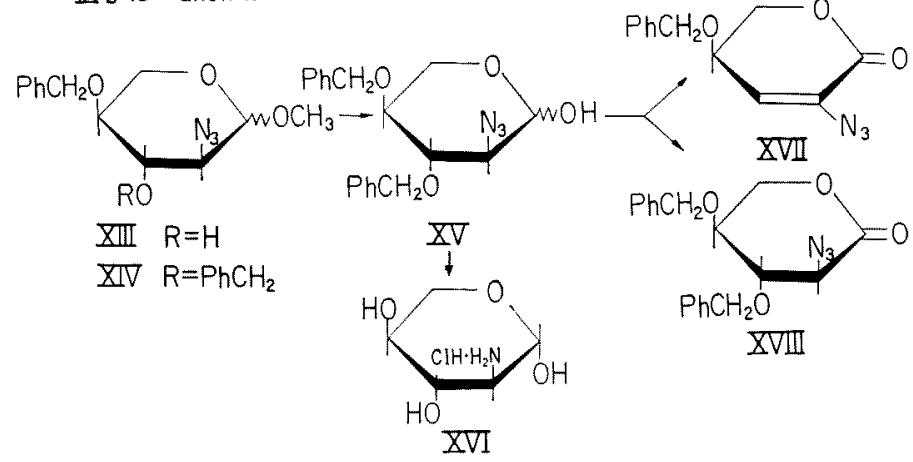

FIG. 1.

the group during or after the migration.* In order to prevent the migration, the hydrogenolysis was attempted in the presence of a base. The hydrogenolysis with palladium on carbon, however, did not proceed at all in the presence of sodium acetate.

Successful hydrogenolysis of II was achieved in liquid ammonia with sodium metal to give III in good yield. After III had been tosylated according to Brimacombe et al., ") the resulting 3-O-tosylate (IV) was treated with sodium azid in an improved way to afford $V$ in crystalline state. NMR spectrum of $\mathrm{V}$ did not reveal a well-resolved pattern for the first order analysis but addition of tris(dipivalomethanato) europium made it possible to assign whole protons. (Fig. 2)

* A similar acid-lability of 1,2-O-isopropylidene group having cis hydroxyl group on the contiguous carbon has been encountered in the other cases. 5,91
5,6-O-Isopropylidene group of $\mathrm{V}$ was selectively hydrolyzed with aqueous acetic acid in two ways. The resulting 3-azido-3-deoxy-1,2O-isopropylidene-L-idofuranose (VI) was tritylated in an usual way to afford 6-O-trityl derivative (VII). The hydroxyl group at C-5 of VII was then benzylated with benzyl chloride and potassium hydroxide to give crystalline 3-azido-5-O-benzyl-3-deoxy-1, 2-O-isopropylidene-6-O-trityl- $\beta$-L-idofuranose (VIII). Simultaneous removal of the isopropylidene and trityl groups from VIII was attempted in aqueous isopropanol with sulfuric acid but it was unsuccessful because of the low solubility of VIII in such aqueous media. Therefore, two steps of reactions consisting of methanolysis and hydrolysis of the resulting methyl glycoside were carried out. Thus, VIII was treated with methanolic hydrogen chloride at room temperature to afford an 


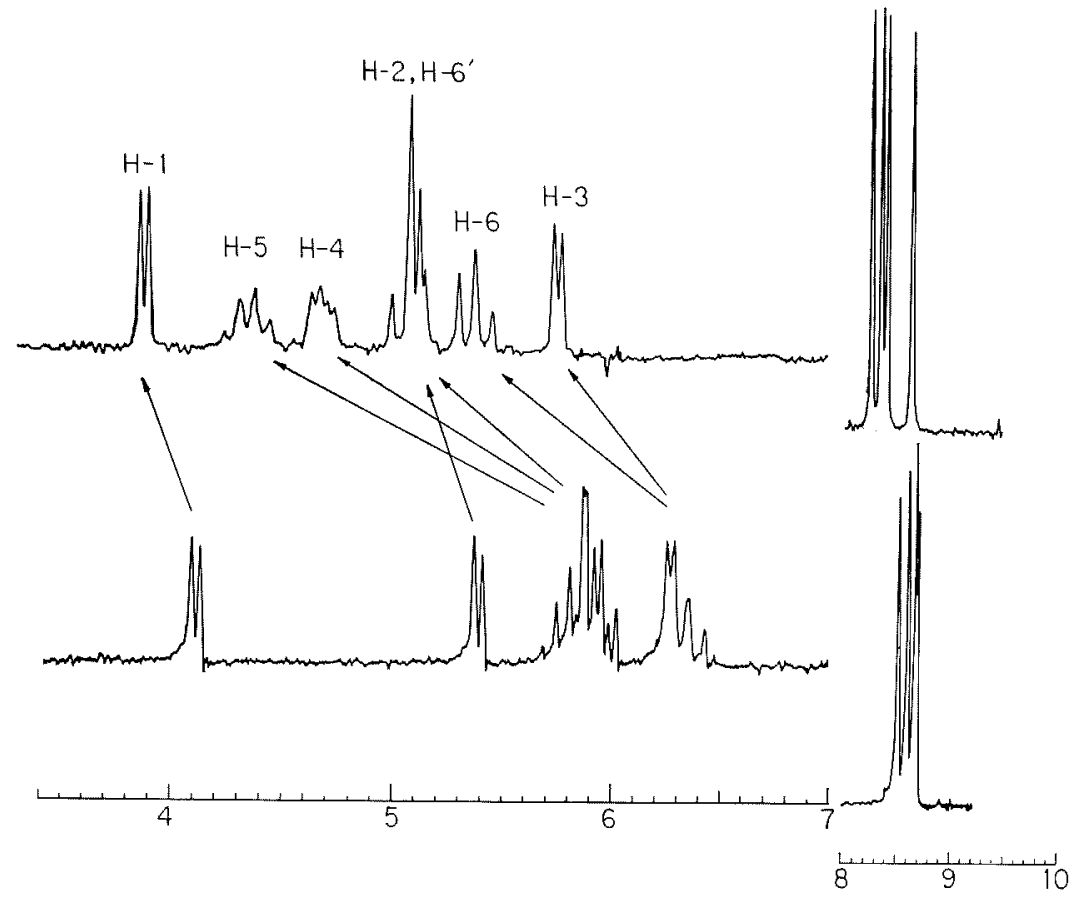

Fig. 2. NMR Spectra (100 MHz) of 3-Azido-3-deoxy-1,2: 5,6-di-O-isopropylidene- $\beta$-L-idofuranose (V) in Carbon Tetrachloride Solution ( $48 \mathrm{mg}$ in $0.7 \mathrm{ml}$ ).

Lower spectrum, the normal spectrum: Upper spectrum, the spectrum after addition of tris (dipivalomethanato) europium $(11.25 \mathrm{mg}$ ). The signals attributable to methyl protons of isopropylidene groups at $\quad 8 \sim 9$ are reduced on $1 / 2$ scale.

anomeric mixture of methyl 3-azido-5-Obenzyl-3-deoxy-L-idofuranoside (IXa and IXb). Both anomers were isolated by column chromatography and identified on the bases of their NMR spectra and optical rotations. An anomeric mixture of IX was then heated in aqueous methanol with hydrochloric acid for hydrolysis of the glycosidic bond. Unexpectedly, the reaction did not proceed to completion and IX (especially $\alpha$-anomer) was detected in the reaction mixture even after $20 \mathrm{hr}$. However, IX was almost completely hydrolyzed with the same acid when the solvent was changed with aqueous isopropanol. The resulting 3-azido-5-O-benzyl-3-deoxy-Lidofuranose ( $\mathrm{X}$ ) was an unstable compound in basic (even in neutral) condition and could not be isolated because of its decomposition during neutralization with base. The fact described above prompted us to oxidize $\mathrm{X}$ with sodium periodate soon after acidic hydro- lysis of IX. The oxidative clevage of $X$ gave two products which moved differently on thin layer chromatography. They were tentatively assigned as 2-azido-4-O-benzyl-2-deoxy-3-Oformyl-L-xylopyranose (XI) and 2-azido-4-Obenzyl-2-deoxy-L-xylopyranose (XII) produced from XI by hydrolysis of its formyl group with acid in the solvent. Those assignments were supported by the fact that the mixture of XI and XII gave only one product identified with methyl 2-azido-4-O-benzyl-2-deoxy-L-xylopyranoside (XIII) on the bases of its elemental analysis and spectral data when the mixture was treated with methanol containing dry hydrogen chloride. The hydroxyl group at C-3 of XIII was benzylated as described for the preparation of VIII to afford methyl 2-azido-3, 4-di-O-benzyl-2- deoxy- L-xylopyranoside (XIV). The glycosidic linkage of XIV was hydrolyzed in acetic acid with aqueous sulfuric acid to give $\mathrm{XV}$ as analytically pure 
syrup. For its structural confirmation, XV was catalytically reduced in the presence of hydrochloric acid to give 2-amino-2-deoxy- $\alpha$ L-xylose hydrochloride (XVI), of which physical properties except the optical rotation agreed with those of the known D-enantiomer. ${ }^{10,11}$ ) The optical rotation of XVI has a reverse sign to that of $D$-enantiomer but reveals a similar mutarotation.

Oxidation of XV with methyl sulfoxideacetic anhydride was carried out as reported previously with partially benzylated 2-azido2-deoxy-D-altropyranose. ${ }^{1}$ Result, however, was quite different from the previous case. At least three spots overlapping each other were detected on thin-layer chromatogram of the oxidation mixture. All attempts to separate each products failed. The mixture, therefore, was roughly divided into two fractions by column chromatography in such a way as the compound corresponding to the middle spot on thin-layer chromatogram was divided into these two fractions. Both fractions had IR absorptions at $1730 \sim 1740$ and $2100 \mathrm{~cm}^{-1}$ attributable to lactone and azido group respectively. The fastly moving fraction (major fraction) had an IR absorption at $1635 \mathrm{~cm}^{-1}$ but the slowly moving fraction (minor fraction) had no absorption in this area. Besides, the major fraction was positive to permanganate test for double bond. On the bases of these results, the existence of an unsaturated lactone was supposed in the major fraction. Catalytic reduction of the major fraction with palladium on carbon gave several ninhydrin-positive products. * Among those products, 2-amino-2,3-dideoxy-L-threopentoic acid (deoxy polyoxamic acid) was detected on thin-layer chromatogram in comparison with an authentic sample isolated from Polyoxin E or G. ${ }^{4}$ From this finding, the unsaturated lactone produced by oxidation of XV was elucidated to be 2-azido-4-Obenzyl-2,3-dideoxy-L-glycero-pent-2-enono-1,5lactone (XVII). Reduction of the minor fraction also gave several products. The $R f$

* Probably partially debenzylated compounds would be in the mixture. value of one of the products on thin-layer chromatogram was identical with that of authentic polyoxamic acid isolated from polyoxins $A \sim L$ (except $E$ and $G$ ). ${ }^{4}$ Therefore, the minor fraction was confirmed to contain 2-azido-3, 4-di-O-benzyl-2-deoxy-L-xylono-1, 5lactone (XVIII).

In conclusion, oxidation of XV with methyl sulfoxide-acetic anhydride gave an unsaturated lactone XVII as major product and XVIII as minor product. One more compound was formed besides these two products. On the bases of the result reported in the previous paper, ${ }^{1}$ the third product may be an epimer of XVIII.

\section{EXPERIMENTAL}

All melting points are uncorrected. Specific rotations were measured with Perkin-Elmer 141 Polarimeter in a $1 \mathrm{dm}$ tube. IR spectra were recorded with Shimadzu IRS-27 spectrometer. NMR spectra were recorded at $60 \mathrm{MHz}$ with Japan Electron Optics C-60 spectrometer and at $100 \mathrm{MHz}$ with Varian $\mathrm{HA} 100-\mathrm{D}$ spectrometer. Column chromatography was performed with silica gel $(0.05 \sim 0.20 \mathrm{~mm}$; E. Merck) and the solvent systems specified.

3-O-Benzyl-1,2:5,6-di-O-isopropylidene- $\beta$ - - -talofturanose (II). Anhydrous cupric sulfate $(19 \mathrm{~g})$ was added to a solution of $I(6.5 \mathrm{~g})$ in anhydrous acetone which was freshly distilled from potassium permanganate and then from Drierite (Hammond Co.). The mixture was stirred under reflux over night. After filtration, the filtrate was concentrated in vacuo to afford a brown syrup ( $7.6 \mathrm{~g}$ ) which crystallized on standing in a refrigerator. Recrystallized twice from $n$-hexane; Yield $5.2 \mathrm{~g}(71 \%) ; \mathrm{mp} 71 \sim 73^{\circ} \mathrm{C},[\alpha]_{0}^{19}$ $+88.3^{\circ}$ ( $c=1.01$, chloroform). Anal. Found: C, 65.31; H, 7.25. Calcd. for $\mathrm{C}_{19} \mathrm{H}_{26} \mathrm{O}_{6}: \mathrm{C}, 65.13 ; \mathrm{H}$, $7.48 \%$.

1,2:5,6-Di-O-isopropylidene- $\beta$-L-talofuranose (III). To a suspension of II $(49 \mathrm{~g})$ in liquid $\mathrm{NH}_{3}$ (1.5 liter) was added sodium metal $(10 \mathrm{~g})$ in portions under stirring at $-50^{\circ}$ Three hours later, ammonium chloride $(20 \mathrm{~g})$ was added to the mixture. After the liquid ammonia was evaporated at room temperature, the resulting residue was suspended in water (1 liter) and extracted with chloroform (1 liter). The extract was washed with water, dried over sodium sulfate and evaporated in vacuo to afford a pale brown syrup (III) which crystallized with agitation in a small amount of cyclohexane. Recrystallized from cyclohexane; Yield $31 \mathrm{~g}(85 \%) ; \mathrm{mp} 79 \sim 80^{\circ} \mathrm{C},[\alpha]_{D}^{24}$ 
$+27.6^{\circ}\left(c=0.93\right.$, chloroform). [literature ${ }^{7]} \mathrm{mp} 85^{\circ} \mathrm{C}$, $[\alpha]_{D}+31.3^{\circ}$ (chloroform)]

1,2:5,6-Di-O-isopropylidene-3-O-p-toluenesulfonyl- $\beta$ L-talofuranose $(\mathrm{IV})$. This compound was prepared according to the literature. ${ }^{7 !}$

3-Azido-3-deoxy-1,2:5,6-di-O-isopropylidene- $\beta$ - $L$ idofuranose $(V)$. To a solution of 3-tosylate (IV, $108 \mathrm{~g}$ ) in HMPA (3 liters) was added sodium azide $(262 \mathrm{~g})$. The mixture was heated at $110^{\circ} \mathrm{C}$ for $10 \mathrm{hr}$ and diluted with water (5 liters). After saturation with sodium chloride, the mixture was extracted with ether ( 7 liters) and the extract was dried over $\mathrm{Na}_{2} \mathrm{SO}_{4}$ and evaporated in vacuo to give the syrupy $\mathrm{V}(81 \mathrm{~g})$ which later crystallized. Recrystallized from $n$-hexane; $\operatorname{mp} 69 \sim 71^{\circ} \mathrm{C},[\alpha]_{\mathrm{D}}^{23}-73.9^{\circ}(c=1.21$, chloroform $)$; [literature ${ }^{7}$ bp $135 \sim 145^{\circ} \mathrm{C}$ (bath) $/ 0.5 \mathrm{mmHg},[\alpha]_{\mathrm{D}}$ $-80.4^{\circ}\left(c=0.51\right.$, chloroform)], $\nu_{\max }^{\mathrm{fllm}} \mathrm{cm}^{-1}: 2100\left(\mathrm{~N}_{3}\right)$, NMR (at $100 \mathrm{MHz}, \mathrm{CCl}_{4}$ solution) :: $6.50 \sim 5.60(5$ protons, multiplet, $\mathrm{H}-3, \mathrm{H}-4, \mathrm{H}-5, \mathrm{H}-6, \mathrm{H}-6^{\prime}$ ), 5.40 (1 proton, doublet, $J_{1,2}=4 \mathrm{~Hz}, \mathrm{H}-2$ ), 4.12 (1 proton, doublet, $J_{1,2}=4 \mathrm{~Hz}, \mathrm{H}-1$ ).

\section{3-Azido-3-deoxy-1,2-O-isopropylidene- $\beta$-L-idofuranose} (IV).

Method A. Water $(2 \mathrm{ml})$ was added dropwise to a solution of $\mathrm{V}(600 \mathrm{mg})$ in acetic acid $(6 \mathrm{ml})$. The mixture was kept at $40^{\circ} \mathrm{C}$ for $4 \mathrm{hr}$ and poured into water $(30 \mathrm{ml})$.

After neutralization with excess of sodium carbonate, the mixture was evaporated in vacuo to dryness. After the residue was extracted with chloroform ( $\mathrm{ca} .100 \mathrm{ml}$ ), the extract was washed with a little water $(c a .20 \mathrm{ml})$, dried over sodium sulfate and evaporated in vacuo to afford the syrupy VI $(400 \mathrm{mg}, 76 \%$ ), which later crystallized. Recrystallized from isopropyl ether; $\mathrm{mp}$ $91 \sim 4^{\circ} \mathrm{C},[\alpha]_{\mathrm{D}}^{22}-63.1^{\circ} \quad(c=0.789$, chloroform $) . \nu_{\max }^{\mathrm{KBr}}$ $\mathrm{cm}^{-1}: 3400(\mathrm{OH}), 2100\left(\mathrm{~N}_{3}\right)$. Anal. Found: C, 44.18; $\mathrm{H}, 6.24 ; \mathrm{N}, 15.98$. Calcd. for $\mathrm{C}_{9} \mathrm{H}_{15} \mathrm{O}_{5} \mathrm{~N}_{3}: \mathrm{C}, 44.08$; $\mathrm{H}, 6.17 ; \mathrm{N}, 17.13 \%$.

Method B. To a solution of V $(7 \mathrm{~g})$ in $p$-dioxane $(80 \mathrm{ml})$ was added aqueous acetic acid $(50 \% \mathrm{v} / \mathrm{v}$, $80 \mathrm{ml}$ ). The mixture was kept at $60^{\circ} \mathrm{C}$ for 3 days, diluted with water $(200 \mathrm{ml})$ and neutralized with excess of sodium carbonate. After evaporation, the resulting residue was extracted with acetone $(250 \mathrm{ml})$. The extract was evaporated in vacuo to give an yellow syrup which crystallized on seeding. Yield $3.8 \mathrm{~g}$ $(63 \%)$. Recrystallized from isopropyl ether; $\mathrm{mp}$ $91 \sim 94^{\circ} \mathrm{C}$.

3-Azido-3-deoxy-1,2-O-isopropylidene-6-O-trityl- $\beta$ - Lidofuranose (VII). Trityl chloride $(1.9 \mathrm{~g}, 6.8 \mathrm{mmole})$ was added to a solution of VI $(1.3 \mathrm{~g}, 5.3$ mmole $)$ in dry pyridine $(10 \mathrm{ml})$ and the mixture was kept at room temperature for 4 days. After complete destruction of excess of trityl chloride by addition of a little water, the mixture was poured into ice-water $(c a .250 \mathrm{ml})$ and stirred until a separated syrup solidified. The precipitate (VII) was filtered, washed with isopropyl ether and dried. Yield $2.5 \mathrm{~g}(97 \%)$. This might be used for the next benzylation without further purification. A part of the crude VII was recrystallized from isopropyl ether. $\mathrm{mp} 147 \sim 150^{\circ} \mathrm{C} ;[\alpha]_{\mathrm{D}}^{21}-55.9^{\circ}(c=1.30$, chloroform). $\quad \nu_{\mathrm{max}}^{\mathrm{K} \mathrm{Br}} \mathrm{cm}^{-1}: 3550(\mathrm{OH}), 2100\left(\mathrm{~N}_{3}\right), 1500$ (benzene ring). Anal. Found: C, 69.02; H, 5.99; N, 8.82. Calcd. for $\mathrm{C}_{28} \mathrm{H}_{29} \mathrm{O}_{5} \mathrm{~N}_{3}: \mathrm{C}, 68.98 ; \mathrm{H}, 6.00 ; \mathrm{N}, 8.62 \%$.

3-Azido-5-O-benzyl-3-deoxy-1, 2-O-isopropylidene-6$O$-trityl- $\beta$-L-idofuranose $(V I I I)$. A mixture of VII $(950 \mathrm{mg})$, powdered potassium hydroxide (ca. $2 \mathrm{~g}$ ) and benzyl chloride $(5 \mathrm{~g})$ was heated at $90 \sim 100^{\circ} \mathrm{C}$ for $2.5 \mathrm{hr}$ under stirring. After the mixture was cooled, it was diluted with water $(50 \mathrm{ml})$ and extracted with ether $(100 \mathrm{ml})$. The extract was washed with water, dried over sodium sulfate and evaporated in vacuo (finally below $1 \mathrm{mmHg}$ ) to afford syrupy VIII, which crystallized by agitation in a little methanol. Recrystallized from methanol. Yield $1 \mathrm{~g}(89 \%)$ $105 \sim 6^{\circ} \mathrm{C}, \quad[\alpha]_{\mathrm{D}}^{23}-67.8^{\circ} \quad(c=0.972, \quad$ chloroform $)$. $\nu_{\max }^{\mathrm{K} \mathrm{Br}} \mathrm{cm}^{-1}: 2100\left(\mathrm{~N}_{3}\right), 1500$ (benzene ring). Anal. Found: $\mathrm{C}, 72.81 ; \mathrm{H}, 6.13 ; \mathrm{N}, 7.55$. Calcd. for $\mathrm{C}_{35} \mathrm{H}_{35} \mathrm{O}_{5} \mathrm{~N}_{3}: \mathrm{C}, 72.77 ; \mathrm{H}, 6.11 ; 7.27 \%$.

Methyl 3-azido-5-O-benzyl-3-deoxy- $\alpha$ (and B)-L-idofuranoside (IXa and IXb). Methanolic hydrogen chloride $(4.5 \% \mathrm{w} / \mathrm{v}, 600 \mathrm{ml})$ was added to a suspension of VIII $(31 \mathrm{~g})$ in methanol (1 liter). The mixture was stirred at room temperature over night protecting from moisture, neutralized with excess of solid sodium bicarbonate and filtered. The filtrate was evaporated in vacuo and the resulting residue was extracted with acetone (ca. $700 \mathrm{ml}$ ). The extract was evaporated in vacuo to afford a brown syrup ( $32 \mathrm{~g}$ ) which solidified. Methanol (ca. $200 \mathrm{ml}$ ) was added to the residue and agitated. The crystals (triphenyl carbinol or its methyl ester) were filtered off and washed with a small amount of methanol $(50 \mathrm{ml})$. Combined filtrate and washings were evaporated in vacuo to afford a brown syrup (IXa and IXb, 20 g) which could be used for the next step (hydrolysis of the glycoside) without further purification.

A part of this syrup (700 mg) was chromatographed on silica gel $(70 \mathrm{~g})$ with chloroform-methanol $(96: 4$ $\mathrm{v} / \mathrm{v}$ ) as eluent. Compound $\mathrm{IXb}(\beta$-anomer) was eluted faster than IXa ( $\alpha$-anomer). For IXb (syrup): yield $284 \mathrm{mg},[\alpha]_{\mathrm{D}}^{23}+114.3^{\circ} \quad(c=0.867$, chloroform $), \nu_{\mathrm{m} m \mathrm{f}}^{\mathrm{film}}$ $\mathrm{cm}^{-1}: 3350 \sim 3300(\mathrm{OH}), 2100\left(\mathrm{~N}_{3}\right), 1500$ (benzene ring). $\mathrm{NMR}$ (at $60 \mathrm{MHz}, \mathrm{CDCl}_{3}$ solution) $\tau 5.05$ (1 proton, doublet, $J_{1,2}=4.5 \mathrm{~Hz}, \mathrm{H}-1$ ). Anal. Found: C, $54.33 ; \mathrm{H}, 6.21 ; \mathrm{N}, 13.09$. Calcd. for $\mathrm{C}_{14} \mathrm{H}_{18} \mathrm{O}_{5} \mathrm{~N}_{3}$ : C, $54.36 ; \mathrm{H}, 6.19 ; \mathrm{N}, 13.58 \%$. For IXa: yield $174 \mathrm{mg}$. Recrystallized from ethyl acetate- $n$-hexane, mp $103 \sim$ 
$105^{\circ} \mathrm{C},[\alpha]_{\mathrm{D}}^{21}-99.0^{\circ}(c=0.823$, chloroform $), \nu_{\mathrm{m} \& \mathrm{x}}^{\mathrm{K} \mathrm{Br}} \mathrm{cm}^{-1}$ : $3370,3300(\mathrm{OH}), 2100\left(\mathrm{~N}_{3}\right), 1500$ (benzen ring). NMR (at $60 \mathrm{MHz}, \mathrm{CDCl}_{3}$ solution) - 5.16 (1 proton, singlet, $\mathrm{H}-1)$. Anal. Found: C, 54.19; $\mathrm{H}, 6.14 ; \mathrm{N}, 13.40$. Calcd. for $\mathrm{C}_{14} \mathrm{H}_{19} \mathrm{O}_{5} \mathrm{~N}_{3}$ : C, 54.36; $\mathrm{H}, 6.19 ; \mathrm{N}, 13.58 \%$.

Methyl 2-azido-4-O-benzyl-2-deoxy-1-xylopyranoside (XIII) via $X$ and $X I, X I I$. A mixture of IXa and IXb $(19 \mathrm{~g})$ was dissolved in isopropanol $(500 \mathrm{ml})$. To the solution was addded aqueous hydrochloric acid ( $2 \mathrm{~N}$, $500 \mathrm{ml}$ ) and the mixture was heated undr reflux for $1.5 \mathrm{hr}$ with stirring. The mixture was diluted with additional hydrochloric acid $(2 \mathrm{~N}, 200 \mathrm{ml})$ and heated for further $2.5 \mathrm{hr}$. After the mixture was cooled in an ice-bath, a solution of sodium periodate $(12 \mathrm{~g})$ in water $(200 \mathrm{ml})$ was added. The mixture was stirred at $0^{\circ} \mathrm{C}$ for $1 \mathrm{hr}$, neutralized with sodium hydrogen carbonate to $\mathrm{pH} 5 \sim 6$, filtered and washed with isopropanol. The combined filtrate and washings were concentrated in vacuo to the volume of several hundred $\mathrm{ml}$ and extracted with ethyl acetate (1.3 liter). The extract was washed with water, dried over sodium sulfate and evaporated in vacuo to afford a brown syrup $(18.6 \mathrm{~g})$ which revealed two spots on t.l.c. using chloroform-methanol $(94: 6 \mathrm{v} / \mathrm{v}$ ). The syrup (XI and $\mathrm{XII}, 18 \mathrm{~g})$ was dissolved in methanol $(800 \mathrm{ml})$ containing dry hydrogen chloride $(28 \mathrm{~g})$. The mixture was heated under reflux for $4.5 \mathrm{hr}$, neutralized with excess of sodium hydrogen carbonate and filtered. The filtrate was evaporated in vacuo to dryness and the residue was extracted with acetone $(500 \mathrm{ml})$. The extract was evaporated in vacuo to afford a brown syrup (XIII) (17.5 g) which chromatographed on silica gel $(800 \mathrm{~g})$ with cyclohexane-ethyl acetate $(7: 2 \mathrm{v} / \mathrm{v})$. Yield $9 \mathrm{~g}[\alpha]_{\mathrm{D}}^{19}$ $-33.7^{\circ}\left(c=1.73\right.$, chloroform). $\nu_{\max }^{\mathrm{film}} \mathrm{cm}^{-1}: 3500(\mathrm{OH})$, $2100\left(\mathrm{~N}_{3}\right), 1500$ (benzene ring). Anal. Found: $\mathrm{C}$, 55.74; $\mathrm{H}, 5.96 ; \mathrm{N}, 14.12$. Calcd. for $\mathrm{C}_{13} \mathrm{H}_{17} \mathrm{O}_{4} \mathrm{~N}_{3}$ : C, $55.91 ; \mathrm{H}, 6.14 ; \mathrm{N}, 15.06 \%$.

Methyl 2-azido-3,4-di-O-benzyl-2-deoxy-L-xylopyranoside $(X I V)$. Powdered potassium hydroxide $(25 \mathrm{~g})$ was added to a solution of XIII $(8.7 \mathrm{~g})$ in benzyl chloride $(50 \mathrm{~g})$. The mixture was heated at $80^{\circ} \sim 90^{\circ} \mathrm{C}$ for $4 \mathrm{hr}$ under vigorous stirring. After the mixture was cooled, it was poured into water and extracted with ether $(500 \mathrm{ml})$. The extract was washed with water, dried $\left(\mathrm{Na}_{2} \mathrm{SO}_{4}\right)$ and evaporated in vacuo (finally below $1 \mathrm{mmHg})$ to give a pale yellow syrup $(11.6 \mathrm{~g})$. The syrup was chromatographed on silica gel (500 g) with benzene as eluent. Yield $9.8 \mathrm{~g}(85 \%) ;[\alpha]_{\mathrm{D}}^{21}+9.7^{\circ}$ $\left(c=1.08\right.$, chlorotorm), $\nu_{\max }^{\mathrm{film}} \mathrm{cm}^{-1}: 2100\left(\mathrm{~N}_{3}\right), 1500$ (benzene ring). Anal. Found: C, 64.79; H, 6.00; $\mathrm{N}, 11.36$. Calcd. for $\mathrm{C}_{20} \mathrm{H}_{23} \mathrm{O}_{4} \mathrm{~N}_{3}: \mathrm{C}, 65.03 ; \mathrm{H}, 6.28$; $\mathrm{N}, 11.37 \%$.

2-Azido-3,4-di-O-benzyl-2-deoxy-L-xylopyranose $(X V)$. Aqueous sulfuric acid $(4.5 \mathrm{~N}, 40 \mathrm{ml})$ was added to a solution of XIV $(4 \mathrm{~g})$ in acetic acid $(80 \mathrm{ml})$. The mixture was heated at $90^{\circ} \mathrm{C}$ for $30 \mathrm{hr}$ under stirring, poured into water and extracted with ether $(400 \mathrm{ml})$. The extract was washed with aqueous $\mathrm{NaHCO}_{3}$ and water, dried $\left(\mathrm{Na}_{2} \mathrm{SO}_{4}\right)$ and evaporated in vacuo to afford a syrup (3.2 g). The syrup was chromatographed on silica gel $(200 \mathrm{~g})$ with cyclohexane-ethyl acetate $(3: 1$ $\mathrm{v} / \mathrm{v})$ as eluent to give the syrupy XV $(1.9 \mathrm{~g}, 50 \%)$. $[\alpha]_{\mathrm{D}}^{23}+12.5^{\circ}\left(c=1.36, \mathrm{CHCl}_{3}\right.$, no mutarotation), $\nu_{\mathrm{max}}^{\mathrm{fil} \mathrm{m}} \mathrm{cm}^{-1}: 3400(\mathrm{OH}), 2100\left(\mathrm{~N}_{3}\right), 1500$ (benzene ring). Anal. Found: C, 63.91; H, 5.71; N, 11.80. Calcd. for $\mathrm{C}_{19} \mathrm{H}_{21} \mathrm{O}_{4} \mathrm{H}_{3}: \mathrm{C}, 64.21 ; \mathrm{H}, 5.96 ; \mathrm{N}, 11.82 \%$.

2-Amino-2-deoxy- $\alpha-L-x y l o s e ~ h y d r o c h l o r i d e ~(L-x y l o s-$ amine hydrochloride, $X V I)$. A solution of $\mathrm{XV}$ $(300 \mathrm{mg})$ in a mixture of $p$-dioxane $(25 \mathrm{ml})$, water $(10 \mathrm{ml})$ and concentrated hydrochloric acid $(0.5 \mathrm{ml})$ was stirred in hydrogen atmosphere in the presence of palladium on carbon $(10 \%)$ until the absorption of hydrogen stopped. After filtration, the filtrate was evaporated in vacto to give a brown syrup which essentially showed one spot on t.l.c. (Avicel) with $n$ propanol-pyridine-acetic acid-water $(15: 10: 3: 10 \mathrm{v} / \mathrm{v})$ as developer. The syrupy XVI was treated with charcoal in methanol and evaporated in vacuo. The residual syrup was allowed to stand at room temperature for several days to crystallize. Yield $30 \mathrm{mg}(20 \%)$ mp $160 \sim 162^{\circ} \mathrm{C}$ (decomposition) $[\alpha]_{\mathrm{D}}^{19}-63.9^{\circ}(5 \mathrm{~min}) \rightarrow$ $-46.3^{\circ}$ (24 hr) ( $c=0.58$, water). [D-enantiomer, $\mathrm{mp}$ $165 \sim 167^{\circ} \mathrm{C}$ (dec.), $[\alpha]_{\mathrm{D}}^{31}+40^{\circ}$ (water, final);10 $\mathrm{mp}$ $168 \sim 170^{\circ} \mathrm{C}$ (dec.), $[\alpha]_{\mathrm{D}}^{22}+45^{\circ}$ (water, $\left.\left.24 \mathrm{hr}\right) .^{11 \mathrm{j}}\right]$ Anal. Found: C, 32.19; H, 6.35; N, 7.47. Calcd. for $\mathrm{C}_{5} \mathrm{H}_{12} \mathrm{O}_{4} \mathrm{NCl}: \mathrm{C}, 32.36 ; \mathrm{H}, 6.52, \mathrm{~N}, 7.55 \%$.

Oxidation of $X V$ with methyl sulfoxide and acetic anhydride. Acetic anhydride $(8 \mathrm{ml})$ was added to a solution of XV ( $1 \mathrm{~g})$ in methyl sulfoxide $(12 \mathrm{ml})$. The mixture was kept at room temperature for 3 days and poured into water. Water was decanted from a resulting syrupy product. The syrupy product was washed with water several times and extracted with ether $(100 \mathrm{ml})$. The extract was dried $\left(\mathrm{Na}_{2} \mathrm{SO}_{4}\right)$ and evaporated in vacuo to afford a yellow syrup (950 mg) which reveals inseparable three spots on t.1.c. with benzene-ethyl acetate $(15: 1 \mathrm{v} / \mathrm{v})$ as developer. This mixture was roughly divided into two fractions by column chromatography with benzene-ether $(20: 1)$ as eluent. Both fractions had absorptions at 1730 $1740 \mathrm{~cm}^{-1}(\mathrm{C}=\mathrm{O})$ and $2100 \mathrm{~cm}^{-1}\left(\mathrm{~N}_{3}\right)$. The fastylmoving fraction $(380 \mathrm{mg}$ ) had an IR absorption at $1635 \mathrm{~cm}^{-1}$ due to a double bond conjugated to the carbony group and gave a positive permanganate test. This fraction was dissolved in aqeous $p$-dioxane $(75 \%)$ and reduced catalytically with palladium on carbon $(10 \%)$ in the presence of hydrochloric acid to afford several products. One product was found to have the same $R f$ value as that of authentic 3-deoxy-polyoxamic 
acid on t.l.c. (Avicel) with n-propanol-pyridine-acetic acid-water $(15: 10: 3: 10 \mathrm{v} / \mathrm{v})$ as developer. The slowly-moving fraction ( $270 \mathrm{mg}$ ) had no absorption in the region of $1600 \sim 1700 \mathrm{~cm}^{-1}$ and did not give a positive permanganate test. Reduction of this fraction also gave several products, one of which had the same $R f$ value as that of authentic polyoxamic acid on t.l.c. (Avicel) with the developing system described above.

Acknowledgements. The authors wish to express their thanks to Dr. K. Isono for gift of the authentic specimens of polyoxamic acid and deoxy polyoxamic acid. Also, they are indeted to Dr. H. Homma and his collaborators for elemental analyses and to Mr. J. Uzawa for measurement of NMR spectra.

\section{REFERENCES}

1) H. Kuzuhara, N. Oguchi, H. Ohrui, and S. Emoto, Carbohydrate Research, 23, 217 (1972).
2) "Advances in Carbohydrate Chemistry and Biochemistry," Vol. 26, ed. by R. S. Tipson and D. Horton, Academic Press Inc., New York, 1971, p. 84.

3) E. L. Eliel, N. L. Allinger, S. J. Angyal and G. A. Morrison, "Conformational Analysis," Interscience Publishers, New York, 1965, p. 362.

4) K. Isono, K. Asahi and S. Suzuki, J. Am. Chem. Soc., 91, 7490 (1969).

5) H. Kuzuhara, H. Terayama, H. Ohrui and S. Emoto, Carbohydrate Research, 20, 165 (1971).

6) A. C. Richardson, ibid., 10, 395 (1969).

7) J. S. Brimacombe, P. A. Gent and J. H. Westwood, J. Chem. Soc. (C), 1970, 1632.

8) H. Ohrui, H. Kuzuhara and S. Emoto, Tetrahedron Letters, 1971, 4267.

9) M. Haga, M. Takano and S. Tejima, Carbohydrate Research, 14, 237 (1970).

10) M. L. Wolfrom and K. Anno, J. Am. Chem. Soc., 75, 1038 (1953).

11) R. Kuhn und G. Baschang, Ann., 628, 193 (1959). 